\title{
UBOM-4, a New Scale for Psychic Function and Energy: General Population Normative Values and Influencing Parameters
}

\author{
Daisuke Gotoh1, Hiroshi Hoshino², Kumi Yoshida3 ${ }^{3}$ Yoshiko Akiyama4, Satoshi Fujimoto5, \\ Emiko Yoshioka ${ }^{4}$, Yumiko Namae ${ }^{4}$, Shin-Ichi Niwa ${ }^{6}$ \\ ${ }^{1}$ Fukushima Prefectural Mental Health and Welfare Center, Fukushima, Japan \\ ${ }^{2}$ Department of Neuropsychiatry, School of Medicine, Fukushima Medical University, Fukushima, Japan \\ ${ }^{3}$ Koriyama Institute of Health Sciences, Fukushima, Japan \\ ${ }^{4}$ NPO Society of Utena's Brief Objective Measures of 4 Axes for Psychic Function and Energy, Fukushima, Japan \\ ${ }^{5}$ Niigata University of Rehabilitation, Fukushima, Japan \\ ${ }^{6}$ Aizu Medical Center, Fukushima Medical University, Fukushima, Japan \\ Email: dskgth@gmail.com
}

How to cite this paper: Gotoh, D., Hoshino, H., Yoshida, K., Akiyama, Y., Fujimoto, S., Yoshioka, E., Namae, Y. and Niwa, S.-I. (2018) UBOM-4, a New Scale for Psychic Function and Energy: General Population Normative Values and Influencing Parameters. Open Journal of Psychiatry, 8, 390-412.

https://doi.org/10.4236/ojpsych.2018.84030

Received: September 10, 2018

Accepted: October 28, 2018

Published: October 31, 2018

Copyright ( 2018 by authors and Scientific Research Publishing Inc. This work is licensed under the Creative Commons Attribution International License (CC BY 4.0).

http://creativecommons.org/licenses/by/4.0/

\section{(c) (i) Open Access}

\begin{abstract}
Objective: We introduce Utena's Brief Objective Measures of 4 Axes for Psychic Function and Energy (UBOM-4), a new brief test battery for evaluating psychic function concerning intellect, emotion, volition, and imagination. To date, insufficient general population data on the UBOM have been collected. This study aimed to establish the normative values for the general population in UBOM-4 and examine the effects of age, sex, and mental health status on the values. Methods: The General Health Questionnaire, 12-item version (GHQ-12) and UBOM-4 were administered to 149 individuals working in or attending professional schools or universities (73 males, 76 females; age: 19 - 65 years). Participants were classified as healthy based on their GHQ-12 responses and psychiatrist interviews. Results: UBOM-4 measures (mean $\pm \mathrm{SD}$ ) were: pulse rate difference (PRD or UBOM-pulse), $-0.72 \pm 4.31$ beats/min; ruler catching time (RCT or UBOM-ruler), $18.42 \pm 3.73 \mathrm{~cm}$; degree of randomness (DOR or UBOM-random), $0.94 \pm 0.18$; mean randomizing time (MRT or UBOM-time), $0.60 \pm 0.31 \mathrm{sec}$. The Baum Test drawings were classified as usual (86\%) and unusual patterns (14\%). Sex effects were observed for RCT (UBOM-ruler) and DOR (UBOM-random), but not for PRD (UBOM-pulse) and MRT (UBOM-time). Therefore, the normative values for RCT (UBOM-ruler) (males: $17.37 \pm 3.25 \mathrm{~cm}$; females: $19.42 \pm 3.90$ $\mathrm{cm}$ ) and DOR (UBOM-random) (males: $0.92 \pm 0.18$; females: $0.95 \pm 0.18$ ) should be differentiated by sex. The patterns of the Baum Test drawings were affected by age, with individuals over 51 years showing the unusual pattern
\end{abstract}


more frequently (42\%). Discussion: Compared to previous results for healthy individuals, the present results were similar for RCT (UBOM-ruler), DOR (UBOM-random), MRT (UBOM-time), and the drawing pattern, but different for PRD (UBOM-pulse). This difference is probably because PRD is sensitive to test situation habituation, sex of examiner, order of subtests, etc. Thus, PRD (UBOM-pulse) should be measured after the subject-examiner relationship stabilizes. Conclusion: Our results suggest that UBOM-4 can be widely used in clinical settings, utilizing the present results as a reference.

\section{Keywords}

UBOM-4, Psychic Function, Normative Value, GHQ-12, Shared Decision Making

\section{Introduction}

In 1996, Utena and Miyake [1] proposed a brief, objective test battery of psychic function that comprehensively assessed intellect, emotion, volition, and imagination (Utena's Brief Objective Measures of 4 Axes of Psychic Function and Energy, abbreviated as UBOM-4 or UBOM). Dr. Hiroshi Utena, a former professor of psychiatry at the Tokyo University who was famous for his research on schizophrenia, passed away in 2014. He had intended to develop a brief objective measure for easily assessing whole psychic function instead of evaluating psychopathology, because objective functional assessment, rather than evaluation of subjective phenomena, would help to facilitate shared decision making between patients and treatment staff. Ideally, such a measure should be brief, fit into daily clinical settings, and be familiar to patients.

Psychic function is generally thought to consist of four factors: intellect, emotion, volition, and imagination [2]. Therefore, UBOM was proposed as a brief psychophysiological test battery to objectively measure and assess these four factors (Figure 1).

As shown in Figure 1, psychic function is the system that regulates human behavior from input to output. Fundamentally, behavior is governed by a parallel combination of stimulus and response sets. Human behavior is further controlled by the operation set that couples the two sets from a higher order. This operation set works while mutually interacting with a widely expanding imagination set. In the four-function model of intellect, emotion, volition, and imagination that comprise psychic function, intellect corresponds to the operation set, emotion to the stimulus set, volition to the response set, and imagination to the imagination set.

Based on this model, UBOM assesses intellect, emotion, volition, and imagination through four subtests: 1) a pulse rate difference test [1],2) a ruler catching test [1],3) a random number generation test [3], and 4) a tree drawing test (Baum Test) [4] [5]. The pulse rate difference test measures stress responses or 


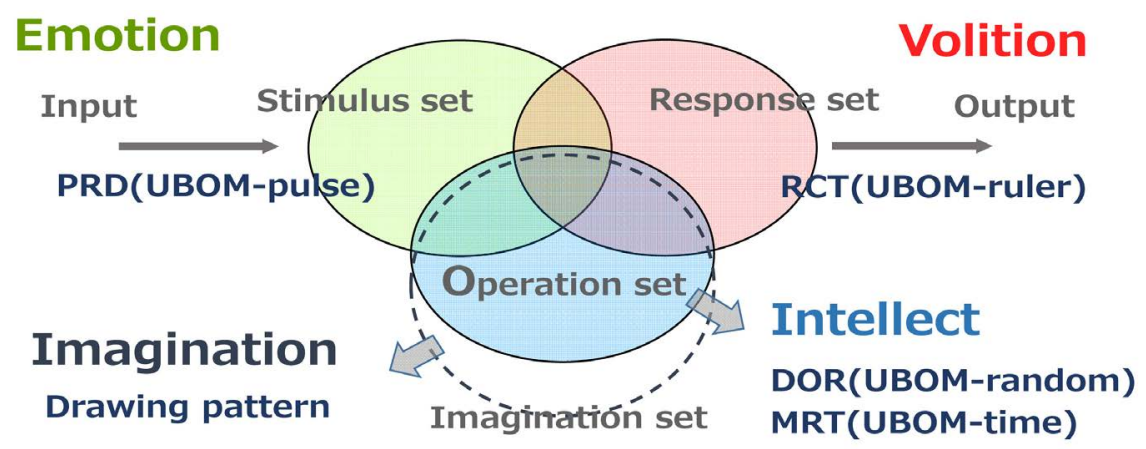

$$
\begin{aligned}
& \text { PRD : Pulse Rate Difference RCT : Ruler Catching Time } \\
& \text { DOR : Degree of Randomness MRT : Mean Randomizing Time } \\
& \text { Drawing pattern : usual } \cdot \text { unusual (positive } \cdot \text { negative } \cdot \text { mixed) }
\end{aligned}
$$

Figure 1. A model of psychic function composed of intellect, emotion, volition, and imagination, the background for the design of Utena's Brief Objective Measures of 4 Axes for Psychic Function and Energy (UBOM-4), and the position of each index obtained by UBOM-4 within this model. (Modified from Utena and Miyake, 1997 [3].)

sensitivities in the autonomic nervous system (emotion); the ruler catching test (reflecting simple reaction time) measures activity and ambition (volition); the random number generation test assesses flexibility of thought (intellect); and the Baum Test provides a representation of the world inside the psyche (imagination). The specifics of the indices derived by each subtest are: the pulse rate difference test calculates pulse rate difference (PRS or UBOM-pulse, in bpm), the ruler catching test measures ruler catching time [RCT (UBOM-ruler), in $\mathrm{cm}$ ], and the random number generation test generates the degree of randomness [DOR (UBOM-random)] and mean randomizing time [MRT (UBNOM-time), in seconds). PRD (UBOM-pulse), RCT (UBOM-ruler), DOR (UBOM-random), and MRT (UBOM-time) are quantitative indices. The Baum Test produces a qualitative index that involves classification of drawing patterns as either usual, positive unusual, negative unusual, or mixed, which bears characteristics of both positive unusual and negative unusual patterns. Utena and Miyake proposed definitions of unusual drawings in contrast to usual drawings as described in section 2.2.2 [5]. Utena and Miyake used UBOM in patients with psychiatric disorders [1] and its clinical usefulness has been gradually established [5].

Standardizing UBOM results for healthy individuals and understanding the factors that may affect the results will be useful for the future use of UBOM. In this study, we administered UBOM to healthy individuals and used the results to develop standard values for UBOM indices among the healthy general population. Further, we investigated the relationship between the results and the subjects' age, sex, and mental health status as captured by the GHQ-12, and explored factors that may influence UBOM results.

\section{Subjects and Methods}

This study was conducted with the approval of the ethical review board of the 
Fukushima Medical University (Approval No. 1017).

\subsection{Subjects}

We recruited subjects among people who are between 19 to 65 years old and participating in the usual social activities. We excluded people from the subjects who are receiving psychiatric treatment. The subjects were participating in usual social activities during the period of at least 1 year before the assessment using UBOM-4.

As shown in Table 1, 149 subjects from the general population who were working [6] or attending school participated in this study after providing written consent ( 73 males [ $39.8 \pm 11.4$ years; median, 39 years; range, 19 to 65 years] and 76 females [34.1 \pm 11.9 years; median, 33 years; range, 19 to 61 years]). DG conducted interviews and confirmed that participants were not receiving treatment for psychiatric disorders. A breakdown of participants by age and sex is shown in Table 1.

\subsection{Methods}

For all 149 subjects participating in this study, the GHQ-12 was administered first, immediately followed by the UBOM. Both were implemented by the same examiner (DG).

\subsubsection{GHQ-12}

Developed from 1960 to 1970 by Goldberg, the GHQ is a self-report-style questionnaire that screens for mild non-psychotic psychiatric disorders. The 12-item edition of the GHQ (GHQ-12) is particularly convenient because of the small number of questions, and its validity is comparable to that of the other editions [7] [8] [9] [10]. A previous study found the cutoff value of 4 points to be most appropriate when the GHQ-12 was used to screen for psychiatric disorders [11], with participants responding on a four-point scale ("Not at all," "Same as usual," "Rather more than usual," and "Much more than usual").

Table 1. Characteristics of the 149 healthy subjects of this study.

\begin{tabular}{ccc}
\hline \multirow{2}{*}{ Workplace category } & \multicolumn{2}{c}{ Subjects characteristics $($ male $\mathrm{n}=73$; female $\mathrm{n}=76)$} \\
\cline { 2 - 3 } Professional/technical & $56(23: 33)$ & Age (median [range $)$ \\
Office work & $14(8: 6)$ & $38[22-59]$ \\
Sales & $16(16: 0)$ & $31.5[20-59]$ \\
Service & $34(7: 27)$ & $43[22-52]$ \\
Safety & $18(18: 0)$ & $32[19-61]$ \\
Construction & $1(1: 0)$ & $39.5[24-58]$ \\
Student & $10(0: 10)$ & $65[65]$ \\
Total & $149(73: 76)$ & $20[19-21]$ \\
& & $36[19-65]$
\end{tabular}


There are two methods of GHQ-12 scoring, the Likert method and the GHQ method [12]. In this study, we used the GHQ method which produces a dichotomous score of 0 or 1; "Not at all" and "Same as usual" responses were scored 0 , and "Rather more than usual" and "Much more than usual" responses were scored 1.

\subsubsection{UBOM}

UBOM index measurement methods are introduced in the following. They are originally explained in the works by Utena [1] [3]:

1) Pulse rate difference test: Examinees were asked to sit and relax in a relatively quiet room. After at least one minute had passed, their resting pulse was measured with wrist palpation for 30 seconds. This pulse rate was doubled and used as the resting heart rate (bpm). Systolic and diastolic blood pressures were measured using a desktop mercury sphygmomanometer or its substitute similar in shape and function to obtain an average of the two pressure values. After this, the cuff of a sphygmomanometer was wrapped again around the upper arm, and the heart beats audible with auscultation were measured for 30 seconds while adding pressure to the obtained average pressure. This heart rate was doubled and used as the heart rate with pressure (bpm). The difference between the heart rate with pressure and the resting heart rate is the pulse rate difference [PRD (UBOM-pulse)].

$$
\operatorname{PRD}(\mathrm{UBOM} \text {-pulse })=(\text { heart rate with pressure })-(\text { resting heart rate })
$$

2) Ruler catching test: Examinees were instructed as follows: "We will now conduct a ruler catching test. This is a test in which you are asked to catch the falling ruler with your dominant hand. The ruler will be dropped with no warning, but please catch it as quickly as possible once it is falling." A $40-\mathrm{cm}$ commercially available plastic ruler was held by the tip and dangled vertically in front of the examinee. Examinees were asked to hold the thumb and index finger of their dominant hand apart with an inside diameter of approximately $5 \mathrm{~cm}$, and the $0 \mathrm{~cm}$ point on the ruler's scale was set at the upper edge of the examinee's thumb and index finger. To bring examinees to a ready state, they were asked to wait with their dominant hand extended, and to heighten their attention, they were told, "Please watch the bottom of the ruler closely." With no warning, the examiner dropped the ruler and the distance $(\mathrm{cm})$ from $0 \mathrm{~cm}$ to the point on the scale at which the examinee grasped the ruler was measured. One practice trial was conducted before the real measurement began. Measurement was conducted five times consecutively. The maximum and minimum values were excluded, and an average drop distance was obtained from the remaining three values. The average drop distance of the three values was entered in the free fall formula, and the reaction time to catch the falling ruler [ruler catching time: RCT (UBOM-ruler)] was obtained.

$$
\operatorname{RCT}(\text { UBOM-ruler })=\frac{1}{5} \sqrt{\frac{L}{2 g}}
$$


(L: average drop distance $(\mathrm{cm})$, g: gravitational acceleration $9.8\left(\mathrm{~m} / \mathrm{sec}^{2}\right)$, RCT (UBOM-ruler): reaction time $(\mathrm{sec})$ ).

Note that the RCT (UBOM-ruler) measure in this study used average drop distance $(\mathrm{cm})$ rather than time (secs).

3) Random number generation test: A pencil and Japanese writing paper with 20 boxes per column were prepared. Examinees were told the following: "We will now conduct a random number generation test. You are asked to write one number in each box on the Japanese writing paper. Please use only numbers from 0 to 9, do not use other numbers. Further, please write the numbers as randomly as possible and continue writing as much as possible for the full one minute without stopping. Please begin with the starting signal and continue with the test until the ending signal is heard. Please do not leave open boxes or columns, and please do not double back without filling in a column from end to end." After taking a break of less than one minute, examinees were told the following: "To continue, please repeatedly write numbers 0 through 9 in order as quickly as possible for one minute. Please begin with the starting signal and continue with the test until the ending signal is heard. Please do not leave open boxes or columns, and please do not double back without filling in a column from end to end." At the signal "ready, begin," examinees repeatedly filled in the consecutive numbers 0 through 9 as quickly as possible. An average random number generation time was obtained from the amount of random and consecutive numbers generated, and a degree of randomness [DOR (UBOM-random)] was obtained from the random numbers written [3]. DOR (UBOM-random) was calculated based on Murakami's formula partially modified by Utena [13].

$$
\operatorname{MRT}(\text { UBOM-time })=60 / N r-60 / N s
$$

( $N r$ random numbers generated, $N s$. consecutive numbers generated)

$$
\operatorname{DOR}(\mathrm{UBOM}-\text { random })=\sum_{\mathrm{i}=0}^{9}|n i / N r-0.1|+\sum_{j=-9}^{+9}|n j /(N r-1)-(10-|j|) / 100|
$$

( $n i$ : number of a particular digit (0 - 9) appeared in the produced sequence, $n j$ : number of a particular digit $(-9-9)$ in calculated first order difference between adjacent digits in the produced sequence.)

MRT (UBOM-time) is the difference between the time necessary to create one random number and the time necessary to create one consecutive number. Random number generation is considered to be the result of subtracting peripheral motor elements from the total time required for generating random numbers (sec). The first item from the DOR (UBOM-random) formula represents the sum of deviations from 0.1 , frequency in a perfectly random sequence, of each digit's frequency (zero-order difference). The second item signifies the sum of deviations from the theoretical frequency in a random sequence of first-order difference between adjacent digits. The smaller the DOR (UBOM-random) value, the higher the randomness. Note that if examinees wanted to rewrite a number during task execution, they were asked to mark that 
it was a correction, for example, with a double underline, and to write over the same area (box). To avoid wasting test time, examinees were asked not to make corrections with an eraser.

4) Tree drawing test (Baum Test): Examinees were instructed as follows: "Please draw one fruit-bearing tree." A specific sheet of paper (white, paper size: B6) was placed vertically in front of the examinee, and they were provided with a $2 \mathrm{~B}$ pencil and an eraser. At this point, the examinee and examiner were seated on either side of the corner of a desk. Examinees were further instructed: "There is no time limit to this test, so please draw without worrying about time." After the examinees finished drawing, they were asked to write a brief comment on the back of the paper about what kind of tree they drew.

The image of the tree drawn was classified as either usual or unusual, and drawings of unusual patterns were further classified into three patterns: positive unusual, negative unusual, or mixed patterns (with both positive unusual and negative unusual characteristics). The definition and classification criteria of the four patterns (usual, positive unusual, negative unusual, mixed unusual) are described below as given in Utena and Miyake [5]. Figure 2 contains examples of actual drawings. The term "pattern classification of images of the trees drawn" is abbreviated as "pattern classification." Pattern classification is based upon the degree of integrity or the gestalt quality of the drawing. The degree of integrity reduces in the order of usual, positive unusual, and negative unusual patterns.

The primary criterion of "usual pattern" is that the integrity or the gestalt quality of a drawing is good. Drawings of the usual pattern include representational sketches, cartoonish figures, and elucidative ideographic pictures. They also include figures with their trunks drawn by single lines but carefully and minutely.

Crude drawings or those with weak pen momentum are classified as a usual pattern if they do not bear features of the abnormal pattern. Drawings without crowns but with trunks open at the end of papers are also classified as usual pattern when they can be regarded as drawn off the edge or they are restricted to limited areas of whole drawings. If the contour of the tree is fuzzy or absent with leaves, fruits, and branches dispersedly drawn, it is still classified as usual pattern if its integrity is intact. Moreover, even if trees are drawn intangible, rough, or thin, they may still be classified as usual pattern if their integrity is recognized as good.

The classification criteria for the positive unusual pattern mainly consist of chaos and leak. Chaos represents the appearance or form of a drawing as a whole that is chaotic. Leak means that the trunk or branches or the top of the crown of a drawing remain open and not closed at their ends. This appearance signifies that the inside and outside of a trunk or branch is linked, with the inside being open to the outside, namely leaked. When the differential classification between chaotic and rough, crude, or intangible features of negative unusual patterns is difficult, it is recommended that drawings with Gestaltzerfall (shape decomposition) be classified as positive unusual pattern. 
Usual Pattern

A1
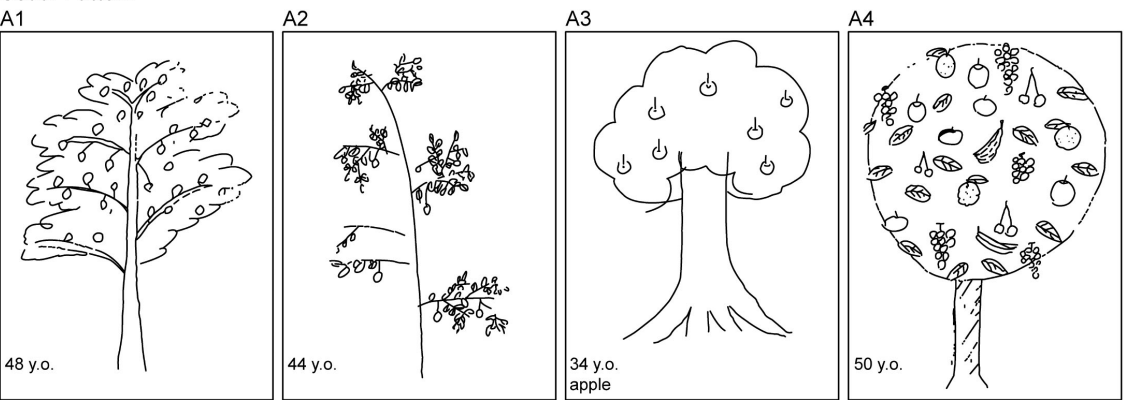

Positive unusual pattern
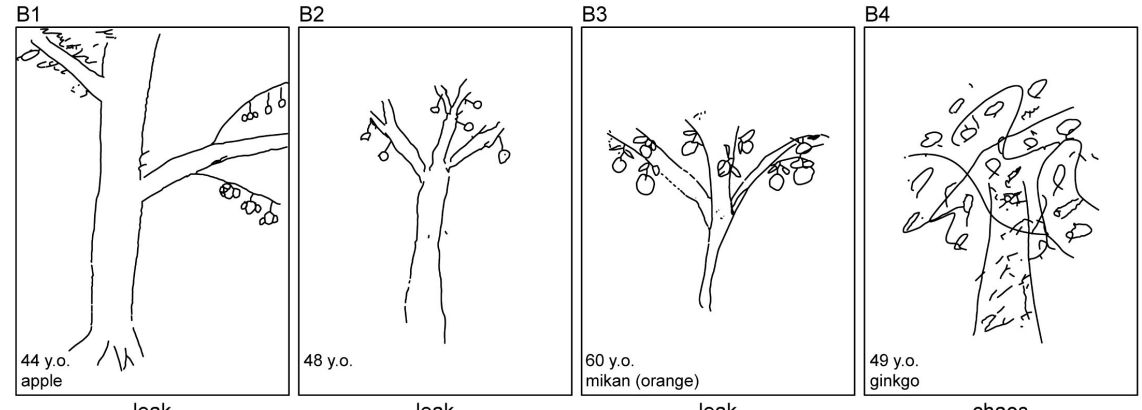

Negative unusual pattern C1
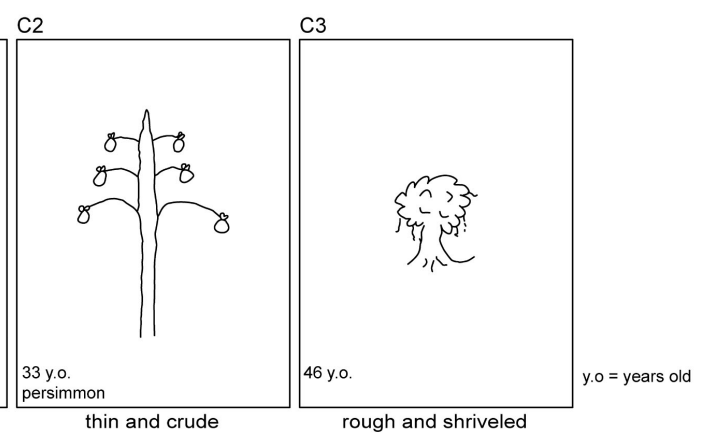

Figure 2. Examples of drawings made in the Baum Test and their classifications (from Utena, Saito, and Miyake, 2001 [5]).

The classification criteria for the negative unusual pattern consist of the following two principal items: 1) more than two of the following six points are satisfied: crude, stiff, intangible, thin, rough, and shriveled, and trunks drawn crudely by single thin lines; 2) drawings judged as intangible, rough, or thin with worse integrity than that of the usual pattern.

The mixed pattern bears characteristics of both the positive and negative unusual patterns described above. Example drawings of usual, positive unusual, and negative unusual patterns are shown in Figure 2: A1 - A4 represent the usual pattern, with B1-B4 illustrating the positive unusual pattern, and C1-C3 the negative unusual pattern. In the four B drawings, $\mathrm{B} 1$ - B3 are examples of leak, and $\mathrm{B} 4$ is of chaos. In the three $\mathrm{C}$ drawings, $\mathrm{C} 1$ is rough and stiff, $\mathrm{C} 2$ is thin and crude, and $\mathrm{C} 3$ is rough and shriveled.

Judgments regarding usual and unusual were all carried out by a sole reviewer. According to Utena and Miyake, the interrater reliability when 205 cases were 
judged for drawing type by two independent raters was high with $\kappa=0.634$; therefore, this method of rating drawing patterns has a certain degree of objectivity [5]. The measured data were entered into the UBOM software (Hitachi Denshi Techno-System, Tokyo, see Appendix 1), and PRD (UBOM-pulse), RCT (UBOM-ruler), DOR (UBOM-random), and MRT (UBOM-time) were calculated. As shown in Figure 3 of Appendix 1, the software calculates PRD (UBOM-pulse), RCT (UBOM = ruler), DOR (UBOM-random), and MRT (UBOM-time). It also produces a cobweb chart as illustrated in Figure 3.

\section{Statistical Analyses}

Values for PRD (UBOM-pulse), RCT (UBOM-ruler), DOR (UBOM-random), and MRT (UBOM-time) were grouped by age, sex, and mental health status as represented by the GHQ-12, and drawing patterns were divided by age, sex, and mental health status and classified into usual, positive unusual, negative unusual, or mixed, where age was grouped into 10 -year increments ( $<31,31$ to 40,41 to $50,>50$ ). Subjects were classified into a high score group and a low score group based on their GHQ-12 scores for a mental health grouping. A lower GHQ-12 score indicates a higher degree of health. To divide subjects into high and low groups so that the number of subjects was not biased toward either group, a total GHQ-12 score of 3 points or above was set as the high group and 2 points or below was set as the low group.

A two-way analysis of variance was conducted to examine the influence of age and sex on mental health status, with GHQ-12 score as the dependent variable and age (4 levels) and sex (2 levels) as independent variables. A three-way analysis of variance was conducted to investigate the influence of sex, age, and mental health status on each index score, with values of PRD (UBOM-pulse), RCT (UBOM-ruler), DOR (UBOM-random), and MRT (UBOM-time) as dependent variables and age (4 levels), sex (2 levels), and mental health status (GHQ-12 [2 levels]) as independent variables. In the drawing pattern classification the number of subjects in the positive unusual, negative unusual, and mixed groups was limited; therefore individuals in these groups were categorized into a single group (unusual drawing). The influence of age, sex, and mental health on usual and unusual drawings was investigated with $\chi$ squared tests and post-test residual analysis.

Statistical analyses were conducted using IBM SPSS Statistics (version 20, United States). The significance level was set at $5 \%$ or lower. Post-hoc analyses were conducted using the Bonferroni method.

\section{Results}

\subsection{GHQ-12 Scores and Effects of Age and Sex}

For the GHQ-12, there were 65 subjects in the high score group with scores of 3 or above and 84 in the low score group with 2 or below. Table 2 summarizes the means and standard deviations of GHQ-12 scores by age and sex. A two-way 
Table 2. Mean score and standard deviation for the GHQ-12 by age and sex.

\begin{tabular}{|c|c|c|c|}
\hline \multicolumn{4}{|c|}{ All ages } \\
\hline & Total & M & $\mathrm{F}$ \\
\hline Mean & 3.03 & 2.10 & 3.92 \\
\hline SD & 3.00 & 2.22 & 3.37 \\
\hline \multicolumn{4}{|c|}{ Age Group $1(<31)$} \\
\hline & Total & M & $\mathrm{F}$ \\
\hline Mean & 3.70 & 3.36 & 3.94 \\
\hline \multirow[t]{3}{*}{ SD } & 2.90 & 2.48 & 3.17 \\
\hline & \multicolumn{3}{|c|}{ Age Group 2 (31 to 40 ) } \\
\hline & Total & M & $\mathrm{F}$ \\
\hline Mean & 3.10 & 2.06 & 3.83 \\
\hline \multirow[t]{3}{*}{ SD } & 2.85 & 2.26 & 3.02 \\
\hline & \multicolumn{3}{|c|}{ Age Group 3 (41 to 50) } \\
\hline & Total & M & $\mathrm{F}$ \\
\hline Mean & 2.31 & 1.60 & 3.50 \\
\hline \multirow[t]{3}{*}{ SD } & 2.97 & 1.67 & 4.19 \\
\hline & \multicolumn{3}{|c|}{ Age Group $4(>50)$} \\
\hline & Total & M & $\mathrm{F}$ \\
\hline Mean & 2.33 & 0.93 & 4.67 \\
\hline SD & 3.31 & 1.58 & 4.15 \\
\hline
\end{tabular}

analysis of variance was conducted with GHQ-12 score as the dependent variable and age and sex as independent variables. The results demonstrated a significant main effect of sex $(F[1,128.664]=15.942, p<0.001)$, with the mean GHQ-12 score being significantly higher for females (F) at $3.92 \pm 3.37$ than for males $(\mathrm{M})$ at $2.10 \pm 2.22$.

\subsection{UBOM in Healthy Individuals}

UBOM test results for the 149 healthy subjects of the present study are shown in Table 3 [PRD (UBOM-pulse), RCT (UBOM-ruler), DOR (UBOM-random), and MRT (UBOM-time)] and Table 4 (drawing patterns).

\subsubsection{Pulse Rate Difference [PRD (UBOM-Pulse)]}

The PRD (UBOM-pulse) results are shown in Table 3. The topmost level displays all ages, the second level age group 1 ( $<31$ years), the third level age group 2 (31 to 40), the fourth level age group 3 (41 to 50), and the bottommost level age group $4(>50)$. The first row in each section displays the total score for both males and females, the second row for males, and the third row for females. For each age group, the left column displays all cases and the second column from the left displays the group divided by GHQ-12 scores. This applies to RCT 
Table 3. Mean value \pm SD for PRD (UBOM-pulse), RCT (UBOM-ruler), DOR (UBOM-random), and MRT (UBOM-time) in all cases by age group. These are divided into the GHQ-12 high score and low score groups. The topmost level displays all ages, the second level age group $1(<31)$, the third level age group 2 (31 to 40 ), the fourth level age group 3 (41 to 50), and the bottommost level age group $4(>50)$.

\begin{tabular}{|c|c|c|c|c|c|c|c|c|c|c|}
\hline & \multicolumn{3}{|c|}{ PRD (UBOM-pulse) (bpm) } & \multicolumn{3}{|c|}{ RCT (UBOM-ruler) (cm) } & \multicolumn{2}{|c|}{ DOR (UBOM-random) } & \multicolumn{2}{|c|}{ MRT (UBOM-time) (sec) } \\
\hline \multicolumn{11}{|c|}{ All ages } \\
\hline $\begin{array}{c}\text { All } \\
\mathrm{n}=149\end{array}$ & $-0.72 \pm 4.31$ & $\begin{array}{c}\text { GHQ-12 } \\
\begin{array}{c}(3 \leq) \\
\mathrm{n}=65 \\
(\leq 2) \\
\mathrm{n}=84\end{array}\end{array}$ & $\begin{array}{l}-0.14 \pm 4.61 \\
-1.18 \pm 4.03\end{array}$ & $18.42 \pm 3.73$ & $\begin{array}{c}\text { GHQ-12 } \\
(3 \leq) \\
\mathrm{n}=65 \\
(\leq 2) \\
\mathrm{n}=84\end{array}$ & $\begin{array}{l}19.11 \pm 4.55 \\
17.88 \pm 2.85\end{array} 0.94 \pm 0.18$ & $\begin{array}{c}\text { GHQ-12 } \\
(3 \leq) \\
n=65 \\
(\leq 2) \\
n=84\end{array}$ & $\begin{array}{l}0.92 \pm 0.16 \\
0.96 \pm 0.20\end{array} 0.60 \pm 0.31$ & $\begin{array}{c}\text { GHQ-12 } \\
(3 \leq) \\
n=65 \\
(\leq 2) \\
n=84\end{array}$ & $\begin{array}{l}0.64 \pm 0.29 \\
0.58 \pm 0.32\end{array}$ \\
\hline $\begin{array}{c}\text { Male } \\
\mathrm{n}=73\end{array}$ & $-0.66 \pm 4.40$ & $\begin{array}{c}\text { GHQ-12 } \\
\begin{array}{c}(3 \leq) \\
\mathrm{n}=25 \\
(\leq 2) \\
\mathrm{n}=48\end{array}\end{array}$ & $\begin{array}{r}0.36 \pm 5.50 \\
-1.19 \pm 3.65\end{array}$ & $17.37 \pm 3.25$ & $\begin{array}{c}\text { GHQ-12 } \\
(3 \leq) \\
\mathrm{n}=25 \\
(\leq 2) \\
\mathrm{n}=48\end{array}$ & $\begin{array}{l}17.21 \pm 4.25 \\
17.45 \pm 2.62\end{array} 0.92 \pm 0.18$ & $\begin{array}{c}\text { GHQ-12 } \\
(3 \leq) \\
n=25 \\
(\leq 2) \\
n=48\end{array}$ & $\begin{array}{l}0.85 \pm 0.15 \\
0.96 \pm 0.19\end{array} 0.56 \pm 0.34$ & $\begin{array}{c}\text { GHQ-12 } \\
(3 \leq) \\
\mathrm{n}=25 \\
(\leq 2) \\
\mathrm{n}=48\end{array}$ & $\begin{array}{l}0.61 \pm 0.35 \\
0.54 \pm 0.33\end{array}$ \\
\hline $\begin{array}{l}\text { Female } \\
\mathrm{n}=76\end{array}$ & $-0.79 \pm 4.25$ & $\begin{array}{c}\text { GHQ-12 } \\
\begin{array}{c}(3 \leq) \\
\mathrm{n}=40 \\
(\leq 2) \\
\mathrm{n}=36\end{array}\end{array}$ & $\begin{array}{l}-0.45 \pm 3.99 \\
-1.17 \pm 4.55\end{array}$ & $19.42 \pm 3.90$ & $\begin{array}{c}\text { GHQ-12 } \\
\begin{array}{c}(3 \leq) \\
\mathrm{n}=40 \\
(\leq 2) \\
\mathrm{n}=36\end{array}\end{array}$ & $\begin{array}{l}20.30 \pm 4.36 \\
18.44 \pm 3.07\end{array} 0.95 \pm 0.18$ & $\begin{array}{c}\text { GHQ-12 } \\
\begin{array}{c}(3 \leq) \\
n=40 \\
(\leq 2) \\
n=36\end{array}\end{array}$ & $0.95 \pm 0.160 .64 \pm 0.27$ & $\begin{array}{c}\text { GHQ-12 } \\
\begin{array}{c}(3 \leq) \\
\mathrm{n}=40 \\
(\leq 2) \\
\mathrm{n}=36\end{array}\end{array}$ & $\begin{array}{l}0.65 \pm 0.25 \\
0.63 \pm 0.25\end{array}$ \\
\hline \multicolumn{11}{|c|}{ Age group $1(<31)$} \\
\hline $\begin{array}{c}\text { All } \\
\mathrm{n}=54\end{array}$ & $-0.11 \pm 5.11$ & $\begin{array}{c}\text { GHQ-12 } \\
(3 \leq) \\
\mathrm{n}=32 \\
(\leq 2) \\
\mathrm{n}=22\end{array}$ & $\begin{array}{c}0.56 \pm 5.14 \\
-1.09 \pm 5.03\end{array}$ & $18.25 \pm 4.43$ & $\begin{array}{c}\text { GHQ-12 } \\
(3 \leq) \\
\mathrm{n}=32 \\
(\leq 2) \\
\mathrm{n}=22\end{array}$ & $\begin{array}{l}18.02 \pm 5.18 \\
18.58 \pm 3.12\end{array} 0.92 \pm 0.18$ & $\begin{array}{c}\text { GHQ-12 } \\
(3 \leq) \\
n=32 \\
(\leq 2) \\
n=22\end{array}$ & $\begin{array}{l}0.90 \pm 0.15 \\
0.93 \pm 0.22\end{array}$ 0.60 \pm 0.30 & $\begin{array}{c}\text { GHQ-12 } \\
(3 \leq) \\
n=32 \\
(\leq 2) \\
n=22\end{array}$ & $\begin{array}{l}0.55 \pm 0.27 \\
0.68 \pm 0.33\end{array}$ \\
\hline $\begin{array}{c}\text { Male } \\
\mathrm{n}=22\end{array}$ & $1.09 \pm 5.97$ & $\begin{array}{c}\text { GHQ-12 } \\
\begin{array}{c}(3 \leq) \\
\mathrm{n}=14 \\
(\leq 2) \\
\mathrm{n}=8\end{array}\end{array}$ & $\begin{array}{l}0.86 \pm 6.80 \\
1.50 \pm 4.54\end{array}$ & $16.67 \pm 3.56$ & $\begin{array}{c}\text { GHQ-12 } \\
\begin{array}{c}(3 \leq) \\
\mathrm{n}=14 \\
(\leq 2) \\
\mathrm{n}=8\end{array}\end{array}$ & $\begin{array}{l}16.35 \pm 4.28 \\
17.23 \pm 1.87\end{array}$ & $\begin{array}{c}\text { GHQ-12 } \\
(3 \leq) \\
n=14 \\
(\leq 2) \\
n=8\end{array}$ & 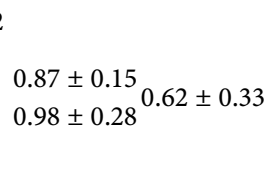 & $\begin{array}{c}\text { GHQ-12 } \\
\begin{array}{c}(3 \leq) \\
\mathrm{n}=14 \\
(\leq 2) \\
\mathrm{n}=8\end{array}\end{array}$ & $\begin{array}{l}0.59 \pm 0.33 \\
0.66 \pm 0.36\end{array}$ \\
\hline $\begin{array}{l}\text { Female } \\
\mathrm{n}=32\end{array}$ & $-0.94 \pm 4.34$ & $\begin{array}{c}\text { GHQ-12 } \\
\begin{array}{c}(3 \leq) \\
\mathrm{n}=18 \\
(\leq 2) \\
\mathrm{n}=14\end{array}\end{array}$ & $\begin{array}{r}0.33 \pm 3.55 \\
-2.57 \pm 4.83\end{array}$ & $19.33 \pm 4.69$ & $\begin{array}{c}\text { GHQ-12 } \\
(3 \leq) \\
\mathrm{n}=18 \\
(\leq 2) \\
\mathrm{n}=14\end{array}$ & $\begin{array}{l}19.32 \pm 5.56 \\
19.35 \pm 3.48\end{array} 0.92 \pm 0.16$ & $\begin{array}{c}\text { GHQ-12 } \\
(3 \leq) \\
n=18 \\
(\leq 2) \\
n=14\end{array}$ & $0.93 \pm 0.14{ }_{0.91 \pm 0.18}^{0.59 \pm 0.28}$ & $\begin{array}{c}\text { GHQ-12 } \\
\begin{array}{c}(3 \leq) \\
n=18 \\
(\leq 2) \\
n=14\end{array}\end{array}$ & $\begin{array}{l}0.52 \pm 0.21 \\
0.69 \pm 0.33\end{array}$ \\
\hline \multicolumn{11}{|c|}{ Age group 2 (31 to 40$)$} \\
\hline $\begin{array}{c}\text { All } \\
\mathrm{n}=39\end{array}$ & $-0.46 \pm 4.05$ & $\begin{array}{c}\text { GHQ-12 } \\
\begin{array}{c}(3 \leq) \\
\mathrm{n}=18 \\
(\leq 2) \\
\mathrm{n}=21\end{array}\end{array}$ & $\begin{array}{l}-0.50 \pm 3.60 \\
-0.43 \pm 4.48\end{array}$ & $18.59 \pm 3.19$ & $\begin{array}{c}\text { GHQ-12 } \\
(3 \leq) \\
\mathrm{n}=18 \\
(\leq 2) \\
\mathrm{n}=21\end{array}$ & $\begin{array}{l}20.02 \pm 3.63 \\
17.37 \pm 2.17\end{array}$ & $\begin{array}{c}\text { GHQ-12 } \\
(3 \leq) \\
n=18 \\
(\leq 2) \\
n=21\end{array}$ & 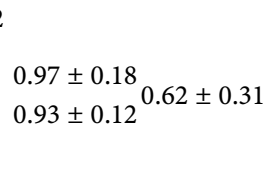 & $\begin{array}{c}\text { GHQ-12 } \\
(3 \leq) \\
n=18 \\
(\leq 2) \\
n=21\end{array}$ & $\begin{array}{l}0.77 \pm 0.31 \\
0.49 \pm 0.26\end{array}$ \\
\hline $\begin{array}{l}\text { Male } \\
\mathrm{n}=16\end{array}$ & $-0.94 \pm 3.75$ & $\begin{array}{c}\text { GHQ-12 } \\
\begin{array}{c}(3 \leq) \\
\mathrm{n}=6 \\
(\leq 2) \\
\mathrm{n}=10\end{array}\end{array}$ & $\begin{array}{c}0.00 \pm 3.29 \\
-1.50 \pm 4.06\end{array}$ & $17.56 \pm 2.97$ & $\begin{array}{c}\text { GHQ-12 } \\
\begin{array}{c}(3 \leq) \\
\mathrm{n}=6 \\
(\leq 2) \\
\mathrm{n}=10\end{array}\end{array}$ & $\begin{array}{l}17.33 \pm 4.02 \\
17.70 \pm 2.39\end{array} 0.93 \pm 0.16$ & $\begin{array}{c}\text { GHQ-12 } \\
\begin{array}{c}(3 \leq) \\
n=6 \\
(\leq 2) \\
n=10\end{array}\end{array}$ & 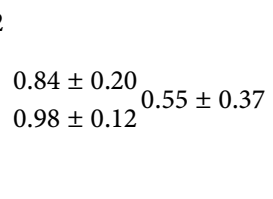 & $\begin{array}{c}\text { GHQ-12 } \\
\begin{array}{c}(3 \leq) \\
n=6 \\
(\leq 2) \\
n=10\end{array}\end{array}$ & $\begin{array}{l}0.78 \pm 0.43 \\
0.40 \pm 0.25\end{array}$ \\
\hline $\begin{array}{c}\text { Female } \\
\mathrm{n}=23\end{array}$ & $-0.13 \pm 4.29$ & $\begin{array}{c}\text { GHQ-12 } \\
\begin{array}{c}(3 \leq) \\
\mathrm{n}=12 \\
(\leq 2) \\
\mathrm{n}=11\end{array}\end{array}$ & $\begin{array}{c}-0.75 \pm 3.86 \\
0.55 \pm 4.80\end{array}$ & $19.31 \pm 3.20$ & $\begin{array}{c}\text { GHQ-12 } \\
\begin{array}{c}(3 \leq) \\
\mathrm{n}=12 \\
(\leq 2) \\
\mathrm{n}=11\end{array}\end{array}$ & $\begin{array}{l}21.36 \pm 2.68 \\
17.08 \pm 2.02\end{array} 0.96 \pm 0.14$ & $\begin{array}{c}\text { GHQ-12 } \\
(3 \leq) \\
\mathrm{n}=12 \\
(\leq 2) \\
\mathrm{n}=11\end{array}$ & $\begin{array}{l}1.03 \pm 0.13 \\
0.89 \pm 0.11\end{array} 0.67 \pm 0.27$ & $\begin{array}{c}\text { GHQ-12 } \\
\begin{array}{c}(3 \leq) \\
\mathrm{n}=12 \\
(\leq 2) \\
\mathrm{n}=11\end{array}\end{array}$ & $\begin{array}{l}0.76 \pm 0.26 \\
0.57 \pm 0.25\end{array}$ \\
\hline
\end{tabular}




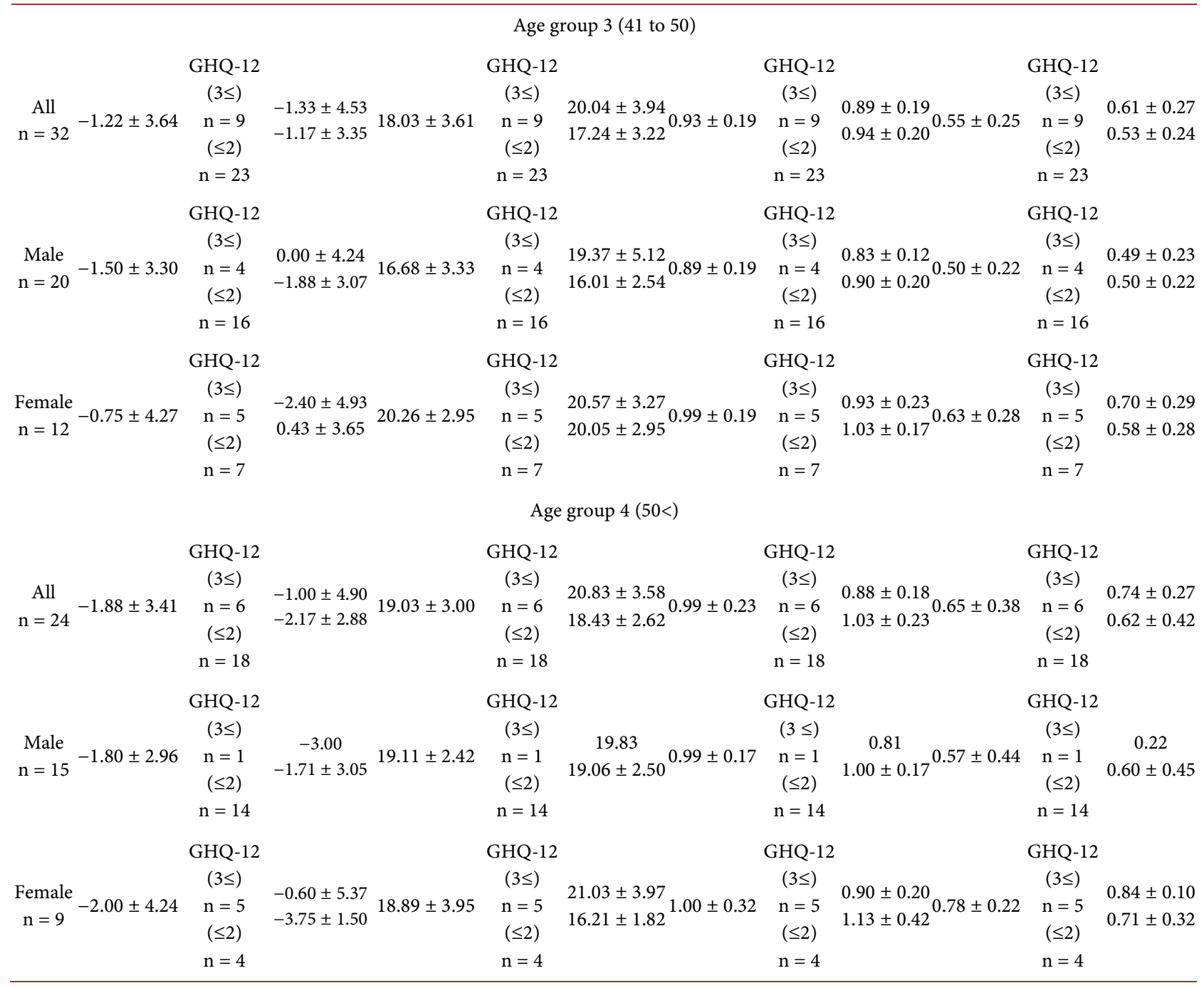

Table 4. Drawing pattern classifications for the Baum Test drawings in all cases by age group. These are divided into the GHQ-12 high score and low score groups. The topmost level displays all ages, the second level age group $1(<31)$, the third level age group 2 (31 to 40 ), the fourth level age group 3 (41 to 50), and the bottommost level age group 4 $(>50)$.

\begin{tabular}{|c|c|c|c|c|c|c|c|c|c|c|}
\hline \multicolumn{11}{|c|}{ Drawing Type } \\
\hline \multicolumn{11}{|c|}{ All ages } \\
\hline & Usual & Neg & Pos & Mix & & & Usual & Neg & Pos & Mix \\
\hline \multirow{3}{*}{$\begin{array}{c}\text { All } \\
\mathrm{n}=149\end{array}$} & \multirow{3}{*}{128} & \multirow{3}{*}{9} & \multirow{3}{*}{10} & \multirow{3}{*}{2} & \multirow{6}{*}{$\begin{array}{c}\text { GHQ-12 } \\
\text { Total Score }\end{array}$} & $(3 \leq)$ & 58 & 3 & 3 & 1 \\
\hline & & & & & & $\begin{array}{c}\mathrm{n}=65 \\
(\leq 2)\end{array}$ & & & & \\
\hline & & & & & & $\mathrm{n}=84$ & 70 & 6 & 7 & 1 \\
\hline \multirow{3}{*}{$\begin{array}{c}M \\
n=73\end{array}$} & \multirow{3}{*}{59} & \multirow{3}{*}{7} & \multirow{3}{*}{5} & \multirow{3}{*}{2} & & $\begin{array}{c}(3 \leq) \\
n=25\end{array}$ & 22 & 2 & 0 & 1 \\
\hline & & & & & & $(\leq 2)$ & & & & \\
\hline & & & & & & $\mathrm{n}=48$ & 37 & 5 & 5 & 1 \\
\hline
\end{tabular}




\section{Continued}

\begin{tabular}{|c|c|c|c|c|c|c|c|c|c|c|}
\hline $\begin{array}{c}\mathrm{F} \\
\mathrm{n}=76\end{array}$ & 69 & 2 & 5 & 0 & & $\begin{array}{c}(3 \leq) \\
\mathrm{n}=40 \\
(\leq 2) \\
\mathrm{n}=36\end{array}$ & $\begin{array}{l}36 \\
33\end{array}$ & $\begin{array}{l}1 \\
2\end{array}$ & $\begin{array}{l}3 \\
1\end{array}$ & $\begin{array}{l}0 \\
0\end{array}$ \\
\hline \multicolumn{11}{|c|}{ Age group $1(<31)$} \\
\hline & Usual & Neg & Pos & Mix & & & Usual & Neg & Pos & Mix \\
\hline $\begin{array}{c}\text { All } \\
\mathrm{n}=54\end{array}$ & 49 & 4 & 1 & 0 & & $\begin{array}{c}(\geq 3) \\
\mathrm{n}=32 \\
(\leq 2) \\
\mathrm{n}=22\end{array}$ & 20 & 2 & 1 & 0 \\
\hline $\begin{array}{c}\mathrm{M} \\
\mathrm{n}=22\end{array}$ & 19 & 3 & 0 & 0 & $\begin{array}{c}\text { GHQ-12 } \\
\text { Total Score }\end{array}$ & $\begin{array}{c}(\geq 3) \\
\mathrm{n}=14 \\
(\leq 2) \\
\mathrm{n}=8\end{array}$ & 12 & 2 & 0 & 0 \\
\hline $\begin{array}{c}\mathrm{F} \\
\mathrm{n}=32\end{array}$ & 30 & 1 & 1 & 0 & & $\begin{array}{c}(\geq 3) \\
\mathrm{n}=18 \\
(\leq 2) \\
\mathrm{n}=14\end{array}$ & 13 & 0 & 1 & 0 \\
\hline
\end{tabular}

Age group 2 (31 to 40 )

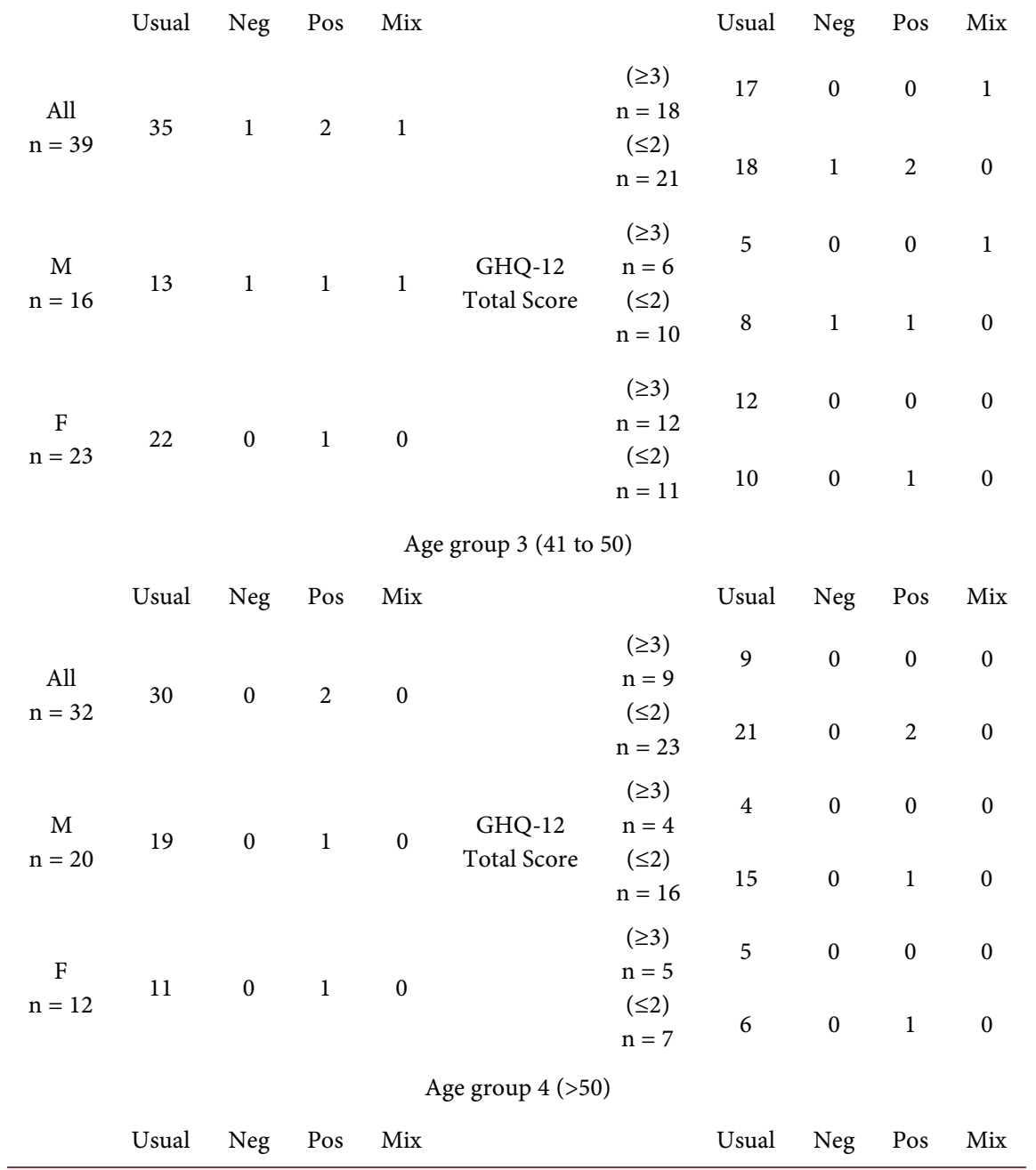




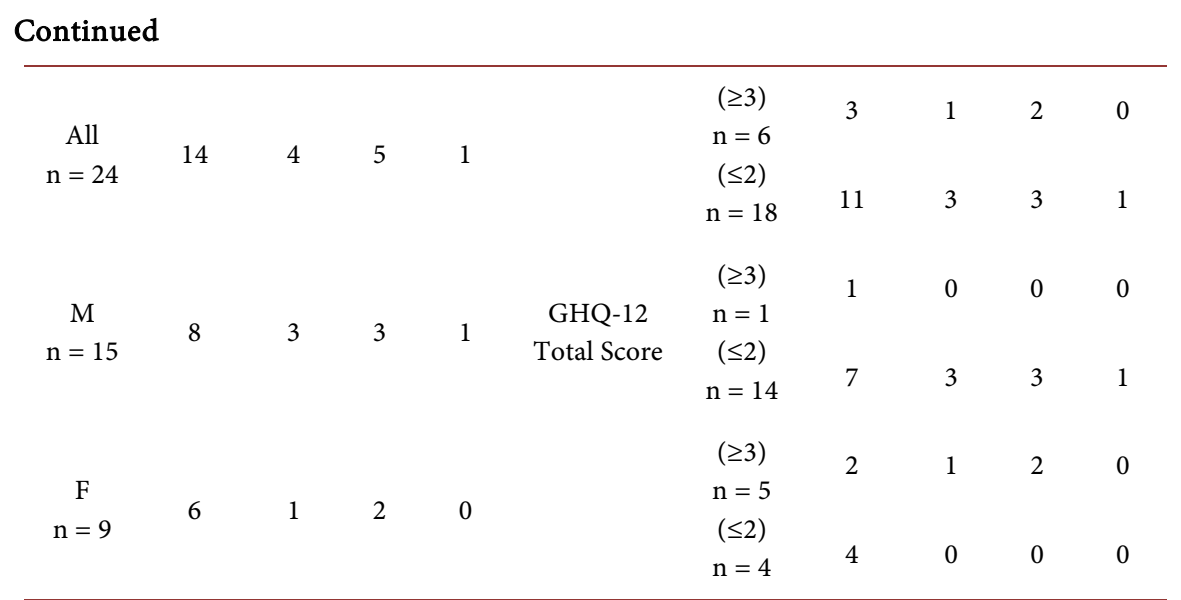

Note: Neg = negative; Pos = positive; Mix = mixed.

(UBOM-ruler), DOR (UBOM-random), and MRT (UBOM-time) in Table 3, and the drawing patterns in Table 4.

PRD (UBOM-pulse) for all ages and both sexes was $-0.72 \pm 4.31 \mathrm{bpm}$ (males, $-0.66 \pm 4.40 \mathrm{bpm}$; females, $-0.79 \pm 4.25 \mathrm{bpm})$. For age group 1 , both sexes, PRD (UBOM-pulse) was $-0.11 \pm 5.11 \mathrm{bpm}$ (males, $1.09 \pm 5.97 \mathrm{bpm}$; females, $-0.94 \pm$ $4.34 \mathrm{bpm}$ ). For age group 2, both sexes, PRD (UBOM-pulse) was $-0.46 \pm 4.05$ bpm (males, $-0.94 \pm 3.75 \mathrm{bpm}$; females, $-0.13 \pm 4.29 \mathrm{bpm}$ ). For age group 3, PRD (UBOM-pulse) was $-1.22 \pm 3.64 \mathrm{bpm}$ (males, $-1.50 \pm 3.30 \mathrm{bpm}$; females, $-0.75 \pm 4.27 \mathrm{bpm}$ ). For age group 4 , PRD (UBOM-pulse) was $-1.88 \pm 3.41 \mathrm{bpm}$ (males, $-1.80 \pm 2.96 \mathrm{bpm}$; females, $-2.00 \pm 4.24 \mathrm{bpm}$ ). The results for the high and low score groups for the GHQ-12 are also displayed in Table 3.

\subsubsection{Ruler Catching Time [RCT (UBOM-Ruler)]}

RCT (UBOM-ruler) results are displayed in Table 3. RCT (UBOM-ruler) for all ages and both sexes was $18.42 \pm 3.73 \mathrm{~cm}$ (males, $17.37 \pm 3.25 \mathrm{~cm}$; females, 19.42 $\pm 3.90 \mathrm{~cm}$ ). For age group 1, RCT (UBOM-ruler) was $18.25 \pm 4.43 \mathrm{~cm}$ (males, $16.67 \pm 3.56 \mathrm{~cm}$; females, $19.33 \pm 4.69 \mathrm{~cm}$ ). For age group 2, RCT (UBOM-ruler) was $18.59 \pm 3.19 \mathrm{~cm}$ (males, $17.56 \pm 2.97 \mathrm{~cm}$; females, $19.31 \pm 3.20 \mathrm{~cm}$ ). For age group 3, RCT (UBOM-ruler) was $18.03 \pm 3.61 \mathrm{~cm}$ (males, $16.68 \pm 3.33 \mathrm{~cm}$; females, $20.26 \pm 2.95 \mathrm{~cm}$ ). For age group 4, RCT (UBOM-ruler) was $19.03 \pm 3.00$ $\mathrm{cm}$ (males, $19.11 \pm 2.42 \mathrm{~cm}$; females, $18.89 \pm 3.95 \mathrm{~cm}$ ). The results for the high and low score groups for the GHQ-12 are also displayed in Table 3.

\subsubsection{Degree of Randomness [DOR (UBOM-Random)]}

DOR results are displayed in Table 3. DOR (UBOM-random) for all ages and both sexes were $0.94 \pm 0.18$ (males, $0.92 \pm 0.18$; females, $0.95 \pm 0.18$ ). For age group 1, DOR (UBOM-random) was $0.92 \pm 0.18$ (males, $0.91 \pm 0.20$; females, $0.92 \pm 0.16$ ). For age group 2 , DOR (UBOM-random) was $0.95 \pm 0.15$ (males, $0.93 \pm 0.16$; females, $0.96 \pm 0.14$ ). For age group 3, DOR (UBOM-random) was $0.93 \pm 0.19$ (males, $0.89 \pm 0.19$; females, $0.99 \pm 0.19$ ). For age group 4 , DOR (UBOM-random) was $0.99 \pm 0.23$ (males, $0.99 \pm 0.17$; females, $1.00 \pm 0.32$ ). The 
results for the high and low score groups for the GHQ-12 are also displayed in Table 3.

\subsubsection{Mean Randomizing Time [MRT (UBOM-Time)]}

MRT (UBOM-time) results are displayed in Table 3. MRT (UBOM-time) for all ages and both sexes were $0.60 \pm 0.31 \mathrm{sec}$ (males, $0.56 \pm 0.34 \mathrm{sec}$; females $0.64 \pm$ $0.27 \mathrm{sec}$ ). For age group 1, MRT (UBOM-time) was $0.60 \pm 0.30 \mathrm{sec}$ (males, 0.62 $\pm 0.33 \mathrm{sec}$; females, $0.59 \pm 0.28 \mathrm{sec}$ ). For age group 2, MRT (UBOM-time) was $0.62 \pm 0.31 \mathrm{sec}$ (males, $0.55 \pm 0.37 \mathrm{sec}$; females, $0.67 \pm 0.27 \mathrm{sec}$ ). For age group 3, MRT (UBOM-time) was $0.55 \pm 0.25 \mathrm{sec}$ (males, $0.50 \pm 0.22 \mathrm{sec}$; females, $0.63 \pm$ $0.28 \mathrm{sec}$ ). For age group 4, MRT (UBOM-time) was $0.65 \pm 0.38 \mathrm{sec}$ (males, 0.57 $\pm 0.44 \mathrm{sec}$; females, $0.78 \pm 0.22 \mathrm{sec}$ ). The results for the high and low score groups for the GHQ-12 are also displayed in Table 3.

\subsubsection{Pattern Classification of Drawings in the Baum Test}

As shown in Table 4, the number of subjects that were classified as usual, positive unusual, negative unusual, and mixed patterns was $128,9,10$, and 2, respectively, for all ages and both sexes (59, 7, 5, and 2 for males, and 69, 2, 5, and 0 for females). For age group 1, the number of subjects that were classified as usual, positive unusual, negative unusual, and mixed patterns was $49,4,1$, and 0 , respectively for both sexes (males, 19, 3, 0, 0; females, 30, 1, 1, 0). For age group 2, the numbers were $35,1,2$, and 1, respectively (males, 13, 1, 1, 1; females, 22, 0, 1, 0 ). For age group 3 , the numbers were $30,0,2$, and 0 , respectively (males, 19, 0 , 1, 0; females, 11, 0, 1, 0). For group 4, the numbers were 14, 4, 5, and 1, respectively (males, 8, 3, 3, 1; females, $6,1,2,0$ ). The results for the high and low score groups for the GHQ-12 are also displayed in Table 4.

\subsection{Effects of Age, Sex, and Mental Health Status (GHQ-12) on the Five UBOM Indices}

\subsubsection{Effects of Age, Sex, and Mental Health Status on PRD (UBOM-Pulse)} A three-way analysis of variance was conducted with $\mathrm{PRD}$ (UBOM-pulse) value as the dependent variable and age (4 levels), sex (2 levels), and mental health status (GHQ-12 [2 levels]) as the independent variables. No significant main effects or interactions were found for age, sex, or GHQ-12 score.

\subsubsection{Effects of Age, Sex, and Mental Health Status on RCT (UBOM-Ruler)} A three-way analysis of variance was conducted with RCT(UBOM-ruler) value as the dependent variable and age (4 levels), sex (2 levels), and mental health status (GHQ-12 [2 levels]) as the independent variables. The results showed significant main effects of $\operatorname{sex}(\mathrm{F}[1,56.489]=4.582, \mathrm{p}=0.034)$ and GHQ-12 $(\mathrm{F}[1$, $74.171]=6.016, p=0.015)$. No other main effects or interactions were observed. The mean and standard deviation of RCT (UBOM-ruler) for males was $17.37 \pm$ $3.25 \mathrm{~cm}$, and for females was $19.42 \pm 3.90 \mathrm{~cm}$. The value for the GHQ-12 low score group was $17.88 \pm 2.85 \mathrm{~cm}$, and for the high score group was $19.11 \pm 4.55$ $\mathrm{cm}$. 


\subsubsection{Effects of Age, Sex, and Mental Health Status on DOR (UBOM-Random)}

A three-way analysis of variance was conducted with DOR(UBOM-random) as the dependent variable and age (4 levels), sex (2 levels), and mental health status (GHQ-12 [2 levels]) as the independent variables. The results showed a significant main effect for sex $(\mathrm{F}[1,0.178]=5.515, \mathrm{p}=0.020)$ and GHQ-12 $(\mathrm{F}[1,0.185]$ $=5.707, \mathrm{p}=0.018)$, and a significant interaction between sex and GHQ-12 (F[1, 0.126] $=3.902, \mathrm{p}=0.050)$. The mean and standard deviation of DOR (UBOM-random) for males was $0.92 \pm 0.18$, and for females was $0.95 \pm 0.18$. The value for the GHQ-12 low score group was $0.96 \pm 0.20$, and for the high score group was $0.92 \pm 0.16$. The post-hoc analysis revealed a significant difference in the GHQ-12 low score group $(0.96 \pm 0.19)$ and high score group $(0.85 \pm$ $0.15)$ ( $p=0.005$ ) for males, but no significant difference between the low and high groups was observed in females.

\subsubsection{Effects of Age, Sex, and Mental Health Status on MRT (UBOM-Time)} A three-way analysis of variance was conducted with MRT (UBOM-time) as the dependent variable and age (4 levels), sex (2 levels), and mental health status (GHQ-12 [2 levels]) as the independent variables. The results showed a significant interaction between age and GHQ-12 (F[1, 0.892] $=3.308, \mathrm{p}=0.022)$. The post-hoc analysis revealed a significant difference in the GHQ-12 low score group $(0.49 \pm 0.26 \mathrm{sec})$ and high score group $(0.77 \pm 0.31 \mathrm{sec})(\mathrm{p}=0.006)$ for age group 2 (31 to 40 years), but no other significant differences were observed.

\subsubsection{Effects of Age, Sex, and Mental Health Status on the Drawing Patterns}

To investigate the effect of age, sex, and mental health status on the drawing patterns, $\chi$-squared tests were performed on the distribution of the usual and unusual drawings for each age group, each sex, and the GHQ-12 low score and high score groups. When the $\chi$-squared value was significant, a residual analysis was also conducted. The effect of age group $\left(\chi^{2}[3]=18.2130, \mathrm{p}<0.001\right)$ on the distribution of the usual and unusual drawing patterns was significant, but significant effects of sex and mental health group were not observed. The residual analysis revealed that the unusual patterns were significantly more common in age group 4 ( $>50$ years old) (10 of $24,42 \%$ ). Table 5 shows the drawing pattern distributions by sex and age. The percentages of usual drawing pattern for each sex and age group were as follows; male, 59/73 (80.8\%): female, 69/76 (90.8\%); age group 1, 49/54 (90.7\%); age group 2, 35/39 (89.7\%); age group 3, 30/32 (93.8\%); age group 4, 14/24 (58.3\%).

\section{Discussion}

\subsection{Subject Characteristics and Sex Difference in GHQ-12 Scores}

This study aimed to introduce UBOM and standardize UBOM results for healthy individuals and to investigate factors that may influence these results. In 
Table 5. The distribution of usual and unusual drawings by age and sex. (a) Drawing pattern in male and female groups; (b) Drawing pattern in each age group.

(a)

\begin{tabular}{ccc}
\hline & Usual drawing & Unusual drawing \\
\hline Male & 59 & 14 \\
Female & 69 & 7 \\
\hline
\end{tabular}

$\chi^{2}(1)=3.0554 \mathrm{p}=0.081$.

(b)

\begin{tabular}{ccc}
\hline & Usual drawing & Unusual drawing \\
\hline Age group 1 & 49 & 5 \\
Age group 2 & 35 & 4 \\
Age group 3 & 30 & 2 \\
Age group 4 & 14 & 10 \\
\hline
\end{tabular}

$\chi^{2}(3)=18.2130 \mathrm{p}<0.001$.

line with this, it was necessary to closely examine whether it was valid to consider the subjects to be healthy individuals. As described in the subjects and methods section, when choosing the subjects, one of the authors, DG (with eight years of experience as a psychiatrist), confirmed through an interview that the subjects were not receiving treatment for a psychiatric disease and were leading a normal social life while either working or attending school. Subjects of various ages and occupations were selected to avoid bias in terms of age or social background. They were employed in various fields, including office work, sales, service (caregiving), safety (firefighting), construction, and student. Thus, we concluded that the subjects were healthy volunteers with no selection bias.

The distribution of the GHQ-12 scores was between 0 and 12 points. If we set a $2 / 3$ cutoff value, 65 (43.0\%) of the 149 subjects were determined to be mentally unhealthy with 3 points or above. However, in recent studies using the GHQ-12 in Japan, for example, in Senba and Shimizu [14], which used technical school students as subjects, scores ranged from 0 to 11 points, and $52.3 \%$ scored three points or above. A large-scale survey in the United Kingdom by Harrison et al. found $28.3 \%$ of those aged 18 to 34 to be unhealthy based on GHQ-12 scores [15], and in a study by Kageyama with hospital nurses as subjects, $54.1 \%$ were found to be unhealthy [16]. Considering this, the $43.0 \%$ in this study with 3 or more points is not high.

Moreover, of all factors influencing the GHQ-12 score, only sex was found to be significant. Females have a higher score on the GHQ-12 than males, and there were more females in the GHQ-12 high score group with scores of 3 or above. Previous studies on sex differences in the GHQ-12 reported that women have higher scores than men and that many high-scorers are women [14] [15] [17] [18] [19]. On the other hand, there are also studies that found no differences between men and women on the GHQ-12 [20] [21] [22]. The results obtained in 
this study are consistent with most existing findings; therefore we cannot conclude that mental health problems exist in the female participants on the basis of high GHQ-12 scores.

\subsection{UBOM in the General Population-Standard Values}

As described in the previous paragraph, we believe that the 149 subjects of the present study can be considered healthy. Thus, the UBOM test results obtained in this study are valid standard values for the general (healthy) population and provide a useful reference for interpreting the UBOM test results of unhealthy individuals, such as psychiatric patients, in the future. In the following, we discuss the validity of the standard values obtained in the present study, and the possible factors influencing these values. Given that we consider the present participants to be healthy individuals, we do not differentiate high and low GHQ-12 scores in the standard values obtained from this study. We also compared the means for each index obtained from this study to the means reported by Utena et al. [3] for 56 healthy individuals.

\subsubsection{Pulse Rate Difference [PRD (UBOM-Pulse)]}

As shown in Table 3, the PRD (UBOM-pulse) for all participants was $-0.72 \pm$ $4.31 \mathrm{bpm}$ (males, $-0.66 \pm 4.40 \mathrm{bpm}$; females, $-0.79 \pm 4.25 \mathrm{bpm}$ ). Because main effects were not observed for age and sex on PRD (UBOM-pulse), all participants are treated as one group. When we set the standard value range for $\mathrm{PRD}$ (UBOM-pulse) from mean $-1 \mathrm{SD}$ to mean $+1 \mathrm{SD}$, we get a range of -5.03 to $3.59 \mathrm{bpm}$. According to Utena, the mean PRD (UBOM-pulse) value was $12.0 / \mathrm{min}$, and a value of $20 / \mathrm{min}$ or above was considered abnormal [23] [24]. In this study, the PRD (UBOM-pulse) was $-0.72 \pm 4.31 \mathrm{bpm}$, which differs from Utena's results $(12.0 \pm 7.3 \mathrm{bpm})$ [3]. There are several reasons for this difference, discussed below.

While conducting an investigation of the interrater reliability for PRD (UBOM-pulse), we noticed that some factors influence PRD (UBOM-pulse): the participant's familiarity with the test setting and the examiner, whether the participant and the examiner were of the same sex, and the order in which the blood pressure measurement was conducted during the UBOM test. Since the results of the interrater reliability are presented elsewhere [25], we will only briefly introduce them here. In the study [25], five examiners who had received training in the UBOM test assessed the same 20 participants. The order of the UBOM test was standardized as follows: pulse rate difference $\rightarrow$ ruler catching $\rightarrow$ random number generation $\rightarrow$ Baum Test. The intraclass correlation coefficients among the five examiners were obtained for PRD (UBOM-pulse), RCT (UBOM-ruler), DOR (UBOM-random), and MRT (UBOM-time), with the concordance rate being calculated for the pattern classification of drawings in the Baum Test. The ICC for RCT (UBOM-ruler) was 0.491; DOR (UBOM-random), 0.528; and MRT (UBOM-time), 0.826. All demonstrated moderate interrater reliability. However, the ICC for PRD (UBOM-pulse) remained low, 0.175. The ICCs for the diastolic 
and systolic blood pressure measures for PRD (UBOM-pulse) were 0.510 and 0.630 , respectively, demonstrating moderate concordance rates. Thus, since only the PRD (UBOM-pulse) concordance rate was low, we hypothesized that the relationship between the examiner and the participant (pair) may affect the tension felt by the participant, which may produce a different effect on PRD (UBOM-pulse) for different pairs, resulting in a low ICC for PRD (UBOM-pulse). In the study [25] where the examiner and participant were fixed and the PRD (UBOM-pulse) measurement was conducted three times in one session with three-minute breaks in between for four sessions, the PRD (UBOM-pulse) ICCs obtained for the second and third times through four sessions were above 0.600 , with the highest ICC being 0.923 . In the pairs with high ICCs, the examiner and participant knew each other well, or the examiner and participant were of the same sex. This result supports our hypothesis, and such an effect appears more likely in PRD (UBOM-pulse), because it is the first test implemented in the UBOM test. In Utena's studies, PRD (UBOM-pulse) and other tests were measured only by him, and the relationship between patients (examinees) and examiner (Utena) was well stabilized.

The finding that PRD (UBOM-pulse) is significantly affected by the relationship between the examiner and the participant suggests that the pulse rate difference test is suitable for measuring the sensitivity in stimulus reception. However, resourceful methods could be used to overcome the oversensitivity of the pulse rate difference test: 1) keep the participant's tension constant, 2) use an examiner who is familiar to the participant, 3) employ an examiner of the same sex as the participant, and 4) administer the pulse rate difference test twice, once before and once after completing the UBOM test, so as to familiarize the participant with the test setting and obtain more reliable results.

\subsubsection{Ruler Catching Time [RCT (UBOM-Ruler)]}

As shown in Table 3, RCT (UBOM-ruler) for all participants was $18.42 \pm 3.73$ $\mathrm{cm}$ (males, $17.37 \pm 3.25 \mathrm{~cm}$; females, $19.42 \pm 3.90 \mathrm{~cm}$ ). Since the main effect of sex was significant, it is necessary to set standard values separately for men and women. When we calculate the standard value as ranging from mean $-1 \mathrm{SD}$ to mean $+1 \mathrm{SD}$, it corresponds to 14.69 to $22.15 \mathrm{~cm}$ for all participants (14.12 to $20.62 \mathrm{~cm}$ for males; 15.52 to $23.32 \mathrm{~cm}$ for females). When Utena and Miyake administered the test in 56 men and women with an average age of 40 years, the mean RCT (UBOM-ruler) was $20.5 \pm 2.0 \mathrm{~cm}$ [3], and RCT (UBOM-ruler) values of $24 \mathrm{~cm}$ or above were considered abnormal [23] [24]. This value is comparable to the result of this study, namely $18.42 \pm 3.73 \mathrm{~cm}$. Utena and his colleagues did not mention a difference between males and females.

\subsubsection{Degree of Randomness [DOR (UBOM-Random)]}

As shown in Table 3, DOR (UBOM-random) for all participants was $0.94 \pm 0.18$ (males, $0.92 \pm 0.18$; females, $0.95 \pm 0.18$ ). As the main effect of sex was significant, it is necessary to set standard values separately for men and women. When 
we calculate the standard value as ranging from mean $-1 \mathrm{SD}$ to mean $+1 \mathrm{SD}$, it corresponds to 0.76 to 1.12 for all participants ( 0.74 to 1.10 for males; 0.77 to 1.13 for females). The DOR (UBOM-random) value when Utena and Miyake administered the test in healthy individuals was $0.95 \pm 0.17$ [3], and a value of 1.1 or above was considered abnormal [23] [24]. This value is comparable to our result, namely $0.94 \pm 0.18$.

\subsubsection{Mean Randomizing Time [MRT (UBOM-Time)]}

As shown in Table 3, MRT (UBOM-time) for all participants was $0.60 \pm 0.31$ sec. The main effects of sex, age, and mental health status were not significant. However, there was a significant interaction between age and GHQ-12 score. When we calculate the standard value as ranging from mean -1 SD to mean +1 $\mathrm{SD}$, it corresponds to 0.29 to 0.91 for all participants. If we calculate the standard value by age group, in age group 1 ( $<31$ years old), it is 0.30 to $0.90 \mathrm{sec}$; in age group 2 ( 31 to 40 ), 0.31 to $0.93 \mathrm{sec}$; in age group 3 (41 to 50 ), 0.30 to $0.80 \mathrm{sec}$; and in age group $4(>50), 0.27$ to $1.03 \mathrm{sec}$. Utena and Miyake [3] reported MRT (UBOM-time) in healthy adults was $0.49 \pm 0.18 \mathrm{sec}$. They also claimed that MRT (UBOM-time) for healthy individuals should be between 0.2 and $1.0 \mathrm{sec}$ [3]. According to their explanation for this, in the random number generation task, information processing time of the brain should not be less than $0.2 \mathrm{sec}$, as evidenced in the data for event-related potential and simple reaction time. In addition, $1.0 \mathrm{sec}$ corresponds to the mean $+2 \mathrm{SD}$ of their healthy subjects, hence MRT (UBOM-time) of $1.0 \mathrm{sec}$ or more is out of the normal range [3]. If we consider the standard value for all participants in this study to be 0.29 to $0.91 \mathrm{sec}$, it nearly matches the values of 0.2 to $1.0 \mathrm{sec}$ set by Utena and Miyake [3].

\subsubsection{The Drawing Patterns}

As shown in Table 4, 86\% (128 of 149) of subjects had usual drawings, and $14 \%$ (21 of 149) produced unusual drawings. Our analyses revealed no effect of sex, but the effect of age was significant with many unusual drawings being observed in age group 4 (>50 years old) (unusual drawing 42\%, 10 of 24 ). Utena and Miyake reported that, in 82 healthy individuals (average age 34 years, 21 to 68 years), 89\% had usual drawings and 11\% had unusual drawings [5]. Of our 149 healthy individuals, $86 \%$ had usual drawings and 14\% had unusual drawings; our results are almost identical to those of Utena and his colleagues. They did not mention a difference among age groups.

\section{Limitation}

UBOM-4 is a new scale originally developed in Japan and utilized only in Japan at this moment. Thus, readers outside Japan may be perplexed by unfamiliar terms used for the introduction and explanation of UBOM-4 in the present report. We apologize for this inconvenience, and we are also sorry for readers' inconvenience caused by the cited references written in Japanese. Regarding UBOM-4, literatures written in other languages than Japanese are limited as it stands. 


\section{Conclusions}

We introduced UBOM-4, a new comprehensive test battery developed by Utena for assessing psychic function in psychophysiological terms. We also attempted to set standard values for UBOM indices in healthy individuals. Among the UBOM indices, the pulse rate difference representing emotion or stimulus processing was revealed to be unstable, possibly depending upon the relationship between the participant and the examiner. However, other indices, ruler catching time, degree of randomness, mean random number generation time, and drawing pattern in the Baum Test, exhibited acceptable interrater reliability coefficients (ICCs). Sex and age demonstrated influence on some indices, hence the standard values should be adjusted accordingly. The standard values for UBOM indices presented in this study roughly matched the values set by Utena and his colleagues.

Patients' active participation in treatment and shared decision making improves the quality of medical care. To encourage patients' active participation in psychiatric treatment, it is necessary to develop scales for assessing psychic function that are shared among patients and treatment staff. UBOM is a brief and objective measure that is familiar and acceptable to patients and therefore suitable for widespread use. The standard values for healthy individuals developed by this study will help in the wide application of UBOM for psychiatric treatment.

\section{Acknowledgements}

This study was partly supported by the Grant-in-Aid for Research C (17K10335) from the Japan Society for the Promotion of Science.

\section{Conflicts of Interest}

The authors declare no conflicts of interest regarding this study on UBOM-4.

\section{References}

[1] Utena, H. and Miyake, Y. (1996) Functional Subtyping of Chronic Schizophrenia on the Combined Use of Reaction Time and Stress Response. Clin Psychiat, 38, 127-133. (In Japanese) https://doi.org/10.11477/mf.1405904036

[2] Utena, H. (2003) A Basic Index of Psychic Function-Devising a Brief Test. JPN J Psychiat Treatment, 18, 1455-1458. (In Japanese)

[3] Utena, H. and Miyake, Y. (1997) Simple Psychophysiological Tests for Daily Clinical Use: With Special Reference to Schizophrenia. Clin Psychiat, 39, 801-808. (In Japanese) https://doi.org/10.11477/mf.1405904372

[4] Koch, C. (1999) The Tree Test: The Tree-Drawing Test as an Aid in Psychodiagnosis Translated by Hayashi, K., Kuniyoshi, M., and Ichitani, T. (1952). Nihon Bunka Kagakusha, Tokyo. (In Japanese)

[5] Utena, H., Saito, O. and Miyake, Y. (2001) Simple Functional Tests in Clinical Practice (3): The Baum Test in Patients with Schizophrenia. Clin Psychiat, 43, 737-744. (In Japanese) https://doi.org/10.11477/mf.1405905072

[6] The Japan Institute for Labor Policy and Training (2011) Fourth Revision, Ministry of Health, Labor and Welfare Occupational Classifications, Occupational Classifica- 
tion Table-Revision History and Details, 16. (In Japanese)

[7] Banks, M.H. (1983) Validation of the General Health Questionnaire in a Young Community Sample. Psychological Medicine, 13, 349-353. https://doi.org/10.1017/S0033291700050972

[8] Goldberg, D.P., Gater, R., Sartorius, N., Ustun, T.B., Piccinelli, M., Gureje, O. and Rutter, C. (1997) The Validity of Two Versions of the GHQ in the WHO Study of Mental Illness in General Health Care. Psychological Medicine, 27, 191-197. https://doi.org/10.1017/S0033291796004242

[9] Goldberg, D.P. and Williams, P. (1988) A User's Guide to the General Health Questionnaire. NFER-Nelson, London.

[10] Lobo, A., Perez-Echeverria, M.J. and Artal, J. (1986) Validity of the Scaled Version of the General Health Questionnaire (GHQ-28) in a Spanish Population. Psychological Medicine, 16, 135-140. https://doi.org/10.1017/S0033291700002579

[11] Honda, S., Shibata, Y. and Nakane, Y. (2001) Screening for Psychiatric Disorders Using the GHQ-12 Item Questionnaire. J Health and Welfare Statistics, 48, 5-10. (In Japanese)

[12] Goldberg, D.P. and Hillier, V.F. (1979) A Scaled Version of the General Health Questionnaire. Psychological Medicine, 9, 139-145. https://doi.org/10.1017/S0033291700021644

[13] The Random Number Test Research Society (1973) Human Random Numbers: The Brain's Prism. Nature (Shizen), 28, 49-57. (In Japanese)

[14] Senba, H. and Shimizu, K. (2011) Mental Health Status of Physical Therapy Students-Assessment Using the General Health Questionnaire 12-Item and the Zung Self-Rating Depression Scale Japanese Edition. Bull Toyohashi Sozo Univ, 15, 99-112. (In Japanese)

[15] Harrison, J., Barrow, S., Gask, L. and Creed, F. (1999) Social Determinants of GHQ Score by Postal Survey. Journal of Public Health, 21, 283-288. https://doi.org/10.1093/pubmed/21.3.283

[16] Kageyama, T., Nishikido, N., Kobayashi, T., Oga, J. and Kawashima, M. (2003) The Relationship of Work Stress to the Mental Health Status of Female Nurses in a Public Hospital. JOita Nursing Health Sci, 4, 1-10. (In Japanese)

[17] Backović, D.V., Zivojinović, J.I., Maksimović, J. and Maksimović, M. (2012) Gender Differences in Academic Stress and Burnout among Medical Students in Final Years of Education. Psychiatria Danubina, 24, 175-181.

[18] Horiuchi, M. and Oda, S. (2011) Relationships between Sleep Pattern and Mental Health in University Students-Insights from Gender Differences. Bull the Northern Regions Lifelong Sports Research Center Hokusho Univ, 2, 75-80. (In Japanese)

[19] Nakamura, M., Morita, M., Haraguchi, K., Umei, N., Yoshimoto, R. and Murakami, S. (2003) Psychiatric Complaints of Freshman in General Health Questionnaire. Rehabilitation Kyouiku Kenkyu, 8, 70-72. (In Japanese)

[20] Matsuda, M., Inami, K. and Okamura, K. (2014) A "Mental Health Survey" in University Students (2)-Considering Counseling Services from an Analysis of Mental Health and Distress. The Fujironso, 58, 11-21. (In Japanese)

[21] Mofidi, N., Ghazinour, M., Araste, M., Jacobsson, L. and Richter, J. (2008) General Mental Health, Quality of Life and Suicide-Related Attitudes among Kurdish People in Iran. International Journal of Social Psychiatry, 54, 457-468. https://doi.org/10.1177/0020764008091663

[22] Niiro, M. and Mori, T. (2001) A Study of the Reliability and Validity of the General Health Questionnaire 12-Item Japanese Version (GHQ-12) Based on Corporate 
Employees. Clin Psychiat, 43, 431-436. (In Japanese)

https://doi.org/10.11477/mf.1405902410

[23] Utena, H. (2003) How to Use the Simple Psychic Test in Clinical Practice. JPN J Psychiat Treatment, 18, 965-973. (In Japanese)

[24] Utena, H., Miyake, Y., Saito, O. and Niwa, S. (2009) Brief Objective Measures for Mental Functions (UBOM). Clin Psychiat, 51, 1173-1184. (In Japanese) https://doi.org/10.11477/mf.1405101536

[25] Yoshida, K., Gotoh, D., Hoshino, H., Akiyama, Y., Fujimoto, S. and Niwa, S. (2018) An Investigation of Degree of Consistency among Examiners in Conducting UBOM-4 (Utena's Brief Objective Measures of 4 Axes for Psychic Function and Energy (in Japanese). Occupational Therapy (in Submission).

\section{Appendix 1}

The UBOM software was originally developed by the NPO Society for UBOM Research, which runs on Windows 98. The software calculates PRD (UBOM-pulse), RCT $(\mathrm{UBOM}=$ ruler), DOR (UBOM-random), and MRT (UBOM-time). It also produces a cobweb chart as illustrated below, which shows the results of PRD (UBOM-pulse), RCT (UBOM-ruler), DOR (UBOM-random), MRT (UBOM-time), and Baum Test based upon the normative values among healthy individuals tentatively set by the Society for UBOM Research. The scales for the Baum Test indicate the drawing pattern classification categories. Thus, they are not analog, but arbitrarily set categorical scales. The blue line indicates the upper limit and the brown line the lower limit of the normative values among healthy individuals. The green line demonstrates results of an example subject. Because Windows 98 is outdated, new analysis software has been developed that runs on Windows 7 Excel 2010, Windows8.1 Excel2010, and Windows8.1 Excel2013. Those who wish to use the new software are encouraged to contact Daisuke Gotoh at dskgth@gmail.com.

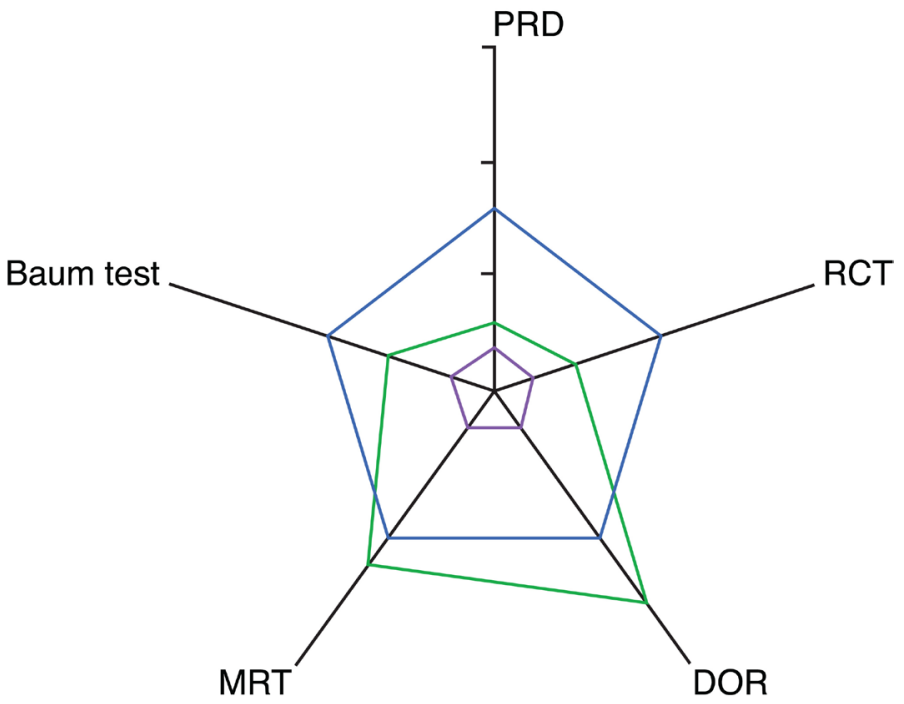

Figure 3. The cobweb chart produced by the original analyzing software. 